\title{
Orientación hacia el Desarrollo del Turismo del Vino de las Webs de las Bodegas de La Rioja y Aragón (España)
}

\author{
Mercedes Marzo-Navarro, Marta Pedraja-Iglesias, Lucia Vinzón'
}

\begin{abstract}
The incorporation of Internet into tourism management enabled the configuration of a distribution channel which is able to promote tourist products and destinations. Websites have become a key factor in modern tourism industry due to their power to stimulate market demand at low cost. In an information-intensive industry websites enhance distribution, customer relationship and information access. This paper is focusing on winery websites of two Spanish regions, and the objective was to evaluate if the websites are used as a tool to develop relationship marketing and to become a wine tourism destination. The results show that about $35 \%$ of wineries have a website, but customer relationships are scarcely developed. Furthermore it detects the existence of a website group focused on wine tourism development, apart from an e-commerce focused group and a basic information group.
\end{abstract}

Keywords: benchmarking; webs; bodegas; marketing de relaciones; análisis cluster; turismo del vino; España, La Rioja, Aragón.

\begin{abstract}
La incorporación de Internet a la gestión de las empresas turísticas ha permitido la configuración de un canal de distribución a través del cual se pueden promocionar productos y destinos turísticos. Las webs se han convertido en un factor crítico para la competitividad de las empresas turísticas, ya que pueden estimular la demanda con un bajo coste. En una industria intensiva en información, las webs permiten mejorar la distribución, la relación con los clientes y el acceso a información. El presente trabajo se centra en las webs de las bodegas de dos zonas de España, con el objetivo de evaluar si son empleadas como herramientas de desarrollo de marketing relacional y como elemento para convertirse en destino del turismo del vino. Los resultados obtenidos muestran que cerca del $35 \%$, de las bodegas poseen webs, estando poco desarrolladas la creación de relaciones con los clientes. Además, se observa la presencia de un grupo de webs orientado al desarrollo del enoturismo, junto a dos grupos orientados a la venta on-line de sus productos y a proporcionar información básica de la empresa.
\end{abstract}

Palabras Claves: benchmarking; website; wineries; relationship marketing; cluster; wine tourism; Spain; La Rioja; Aragón.

\footnotetext{
' Departamento de Economía y Dirección de Empresas, Universidad de Zaragoza. Gran Vía 2, 50005 Zaragoza (España).

Tel.: 349767610 00. Email: mmarzo@unizar.es; mpedraja@unizar.es; luciavinzon@gmail.com
} 


\section{Introduction}

Las últimas décadas se han caracterizado por un rápido desarrollo de las tecnologías de la información (TIC), entre las que destaca Internet. Internet ha modificado la forma de realizar transacciones, ofreciendo distintos tipos de información e incrementando la utilidad y eficiencia de los sistemas de distribución (Kim et al., 2007). De esta manera, las TIC han puesto a disposición de las empresas herramientas que les permiten estimular la demanda de manera relativamente económica. Una de estas herramientas la constituyen las páginas webs, a través de las cuales las empresas pueden ofrecer información sobre los productos que ofertan al mercado (Kittle y Ciba, 1999). Las webs suponen una oportunidad excepcional para la construcción de relaciones empresacliente a través de su personalización e interactividad (Hu et al., 2005).

El CRM (Customer Relationship Management) comprende el negocio y la estrategia de marketing que integra tecnología, procesos y todas las actividades alrededor del cliente (Anton, 1996; Anton, Hoeck, 2002). Internet proporciona una plataforma para distribuir funciones CRM en la web (e-CRM). Así, a medida que los negocios se mueven hacia la web, el e-CRM se mueve hacia el plano central de la estrategia (Feinberg, Kadam, 2002). Además, se ha demostrado el impacto, directo e indirecto, que el CRM y e-CRM tienen sobre la satisfacción del cliente, las ventas, los beneficios y la lealtad (Anton, Hoeck, 2002; Connelly, Yoger, 200I; Cusack, 1998; Swift, 200I; Tschol, 200I). Junto a esto, se observa que las organizaciones están incrementando la aplicación de los conceptos de Marketing Relacional a los mercados de masa (Bhattacharya, Bolton, 2000). Este enfoque tiene por objetivo el desarrollo de vínculos más fuertes con los clientes que, generalmente, se llevan a cabo a través de programas de retención de clientes, gestión de la lealtad, o estrategias de marketing one-toone (Reichheld, 1996). Muchas de estas prácticas de marketing son posibles gracias a los avances de las TIC y de la disponibilidad de nuevos foros de intercambio como Internet (Kittle, Ciba 1999).

Así, el sector turístico ha sido uno de los primeros sectores en adaptar las TIC a sus procesos (Reinders, Baker, 1998). La incorporación de Internet como herramienta de gestión ha facilitado la comercialización de los productos turísticos, constituyendo una fuente de información y de conocimiento para todo tipo de consumidor. Internet ha permitido la configuración de un canal de distribución a través del cual se pueden promocionar los destinos y productos turísticos. De esta manera, Internet se ha convertido en un factor crítico para la competitividad de las organizaciones del sector turístico, dada su capacidad para desarrollar productos turísticos y para crear una red dinámica entre cliente y empresa (Buhalis, Law 2008).

Dentro del sector turístico, el turismo del vino, que se puede definir como la experiencia de visitar viñedos, bodegas, festivales y demostraciones del vino en el cual la cata del vino y/o la experiencia de los atributos del vino son el principal motivo para los visitantes (Hall et al., 2000), está emergiendo como un creciente sector lucrativo en países como Australia, Nueva Zelanda o Estados Unidos (O’Neill y Palmer, 2004). Así, el interés por el producto vino se transforma en el deseo de visitar las zonas productoras (Getz, 2000).

Al igual que en otros países productores, como Australia, EEUU, Chile, etc., en determinadas zonas de España se está apostando por el desarrollo del enoturismo. Este tipo de turismo posee el potencial de proporcionar ventajas competitivas a las regiones productoras de vino y de generar negocios rentables para las bodegas, para otros productos relacionados con el vino y para diversos servicios. Así, los beneficios del enoturismo se pueden trasladar a toda una región, por lo que emerge como un valioso componente de la diversificación rural y del desarrollo económico al actuar como generador de ingresos (Yuan et al., 2005). En este contexto, el papel que pueden desempeñar las webs de las bodegas como elemento de comunicación del turismo del vino es crucial, ya que se ha observado que cerca del 10\% de los enoturistas visitan las bodegas después de visitar sus páginas webs ${ }^{2}$ (Richardson, 2002).

Son diversos los estudios académicos que reflejan la importancia de Internet como herramienta de marketing, pudiéndose identificar tres categorías de estudios en función del objetivo que se pretende. Así, los objetivos perseguidos se centran en: i) identificar las percepciones y requerimientos de los usuarios de las páginas webs; ii)

\footnotetext{
2 El turista del vino suele tener un alto nivel educativo, alta renta y gran interés en el vino (Levine, Pownall, 2004; Yuan et al., 2005) e Internet es de uso común en este segmento de personas.
} 
analizar las aplicaciones prácticas acerca de cómo los sitios webs pueden potenciar las ventas; $y$, iii) evaluar los sitios webs existentes en cierto sector 0 industria (Klassen, 2002). El presente estudio se enmarca en la tercera de estas categorías, ya que su objetivo principal consiste en analizar las webs de las bodegas situadas en dos zonas españolas productoras de vinos de calidad, La Rioja y Aragón. Así, se pretende determinar si las bodegas emplean las webs como herramienta para construir y mantener relaciones con sus clientes, intentando determinar, simultáneamente, la existencia de webs orientadas al desarrollo de un negocio complementario en auge, como es el caso del enoturismo. Las bodegas cuyas webs se analizan están en zonas geográficamente próximas, en el noreste de España, poseen vinos con Denominación de Origen ${ }^{3}$ pero difieren en el grado de desarrollo del enoturismo. Así, en Aragón se encuentra en sus inicios, aunque es percibida como un potencial destino de turismo del vino, mientras que La Rioja es un destino reconocido y afianzado (Ikerfel, 2005).

\section{Dimensiones de las Webs de las Bodegas}

El establecimiento de relaciones y redes de contacto continuas con los clientes se está convirtiendo en el objetivo clave de gran parte de los esfuerzos de marketing de las empresas. Para ello es importante la recolección de información y la creación de una atmósfera de confianza, satisfacción y compromiso a través de programas publicitarios, cooperación entre usuarios, clubs de usuarios, revistas para clientes, etc. Internet ha agrupado estas actividades, transformándose en una poderosa herramienta que puede ser usada por el marketing relacional (Bauer et al., 2002). Así, Internet constituye una innovadora herramienta para la construcción de las relaciones con los clientes, debido a su disponibilidad constante de información, su interactividad, la transferencia eficiente de información, la posibilidad de individualizar la comunicación así como la

\footnotetext{
3 Según el Reglamento (CE) No 510/2006 se entiende por "Denominación de Origen" el nombre de una región, de un lugar determinado o de un país, que sirve para designar un producto agrícola o un producto alimenticio: i) originario de dicha región, de dicho lugar determinado o de dicho país, ii) cuya calidad o características se deban fundamental o exclusivamente al medio geográfico con sus factores naturales y humanos, y iii) cuya producción, transformación y elaboración se realicen en la zona geográfica delimitada.
}

integración de la comunicación y las transacciones al ofrecer la posibilidad de comprar bienes y servicios (Bauer, et al., 2002).

Por lo tanto, Internet mejora la distribución, la relación con los clientes y el acceso a la información en una industria intensiva en información, como es el caso de la industria del turismo (Nysveen et al., 2002; Murphy y Tan, 2003; O'Connor, 2003). Así, por ejemplo, se ha demostrado la existencia de una relación positiva entre satisfacción con la información proporcionada por los sitios webs de la industria hotelera y las intenciones de comportamiento de los turistas potenciales (Jeong et al., 2003) o la relación positiva entre la cantidad de características e-CRM de la web y la satisfacción de los clientes con la misma (Feinberg, Kadam, 2002).

El negocio turístico necesita comunicaciones rápidas, fiables y seguras que permitan comercializar los productos desde puntos de oferta alejados de los puntos de venta (Martín, 1999). A través de Internet los turistas potenciales pueden buscar información sobre ofertas, productos, precios, etc., que les ayuden en su proceso de toma de decisiones. Este comportamiento ya está tomando relevancia en España, como lo demuestra el hecho que, en el 2008 , el $54 \%$ de los turistas utilizó la red para hacer sus consultas, reservas o pagos a través de Internet (EGATUR, 2008). Por lo tanto, si se desea desarrollar un nuevo tipo de turismo, como es el caso del turismo del vino, es necesario conseguir la efectividad de las páginas webs en las que esté presente.

Son numerosos los estudios realizados que analizan la efectividad de las webs $y$ de las herramientas de marketing on-line (Gilbert et al., 1999; Feinberg, Kadam, 2002; Schegg et al., 2002; Nysveen et al., 2002; Scharl et al., 2004; Han, Mils, 2006), aunque escasas las aplicadas al sector turístico (Hashim et al., 2007; Schegg et al., 2002). A modo de ejemplo, en el Cuadro I se muestran las dimensiones de efectividad de las webs de la industria hotelera. 


\begin{tabular}{|c|c|c|}
\hline AUTOR & DIMENSIONES & SUBDIMENSIONES \\
\hline \multirow{15}{*}{ Hashim et al. (2007) } & \multirow{5}{*}{ Información y Procesos } & Ventas o Reservas \\
\hline & & Información de Contacto \\
\hline & & Promoción de Ventas \\
\hline & & Bienes y Servicios \\
\hline & & Hotel \\
\hline & \multirow{2}{*}{ Valor Agregado } & Información de Viajes \\
\hline & & Entretenimiento \\
\hline & \multirow{2}{*}{ Relaciones } & Lealtad/CRM \\
\hline & & Interés Personal \\
\hline & \multirow{3}{*}{ Diseño y Usabilidad } & Navegación \\
\hline & & Técnica \\
\hline & & Medida del Éxito \\
\hline & \multirow{3}{*}{ Confianza } & Copyright y Seguridad \\
\hline & & Temporalidad \\
\hline & & Marca \\
\hline \multirow{18}{*}{ Shegg et al. (2002) } & \multirow{9}{*}{ Servicios y Procesos } & Acceso y Navegación \\
\hline & & Entretenimiento \\
\hline & & Reserva On-Line \\
\hline & & Opciones de Pago \\
\hline & & Información de Precios \\
\hline & & Información General \\
\hline & & Información de Servicios \\
\hline & & Información de la Habitación \\
\hline & & Información para Segmentos Especiales de Clientes \\
\hline & \multirow{2}{*}{ Relación con el Cliente } & Uso de Bases de Datos \\
\hline & & Comunicación \\
\hline & \multirow{4}{*}{ Creación de Valor } & Links Externos \\
\hline & & Valor Agregado \\
\hline & & Información de la Región \\
\hline & & Incentivos \\
\hline & \multirow{2}{*}{ Creación de Confianza } & Implícita \\
\hline & & Explícita \\
\hline & \multicolumn{2}{|l|}{ Cybermarketing } \\
\hline
\end{tabular}

Cuadro I. Dimensiones de Efectividad de las Webs Hoteleras. Fuente: Elaboración Propia.

En el caso del turismo del vino, la revisión de la literatura especializada pone de manifiesto los escasos estudios existentes referidos al uso de las TIC como herramienta de marketing. En este tipo de turismo, cuyos viajes se basan en la experiencia, el poder de mercado radica en usar tecnologías de información para satisfacer las necesidades de conocimiento de los clientes (Olsen y Connolly, 2000). El avance de Internet introduce nuevas oportunidades de marketing para las bodegas, que necesitan crear y mantener sitios webs para, entre otros objetivos, conseguir ventas directas a clientes, realizar marketing directo y promover el turismo del vino (Sellito, 2005). Son importantes los beneficios que Internet ofrece a este sector, tal como la interacción intra-industrial, la mejora de la imagen del negocio y de la presencia de marca, y el aumento de visitantes (Sellito, 2005). A través de sus páginas webs las bodegas pueden desarrollar su imagen, diferenciándose de la competencia, educando al 
consumidor y creando interés en la bodega y en el vino. Si los consumidores nunca han visitado la bodega o probado su vino, la página web crea una importante primera impresión acerca de la calidad del vino y de la bodega (Nowak, Newton, 2008). Por lo tanto se hace necesario profundizar en esta área de conocimiento. Sin embargo, las bodegas se encuentran con dificultades a la hora de transferir parte de su negocio al medio electrónico, debido a problemas con la velocidad de carga del sitio web, la seguridad en los medios de pago on-line, la confianza del cliente, etc. (Richardson, 2002).

Las investigaciones realizadas en Australia por Sellito et al. (2003) y Murphy et al. (2005) son de las escasas existentes que analizan las páginas webs de las bodegas. Sellito et al. (2003) examinan las páginas de 86 bodegas, determinando la existencia de las 3 dimensiones mostradas en el Cuadro 2. Los principales resultados del estudio indican que la tasa de adopción de páginas webs de las bodegas, en el $200 \mathrm{I}$, es del 10\%, porcentaje inferior al de pequeñas y medianas empresas de otros sectores del país. Además, observaron que las pequeñas bodegas orientan sus webs a la venta online ya que esta herramienta les permite llegar a un mayor mercado a un menor coste.

Murphy et al. (2005) se centran en determinar las características de las webs y los procedimientos de e-mail utilizados por 7 bodegas australianas y I estadounidense. Para la evaluación de las webs consideran las 5 dimensiones mostradas en el Cuadro 2. Para analizar cómo responden las bodegas a los e-mails de supuestos clientes o interesados realizan la técnica del mystery shopper. Los resultados obtenidos muestran que las webs se encuentran en la primera etapa de su evolución, ya que se centran en proporcionar información básica, visual y de confianza, mostrando debilidad en la oferta de información social y virtual, en navegabilidad y marketing relacional.

Como se puede deducir de la observación del Cuadro 2, ninguno de los estudios considerados detectan una orientación de las webs analizadas hacia el desarrollo del turismo del vino.

\begin{tabular}{|l|l|l|}
\hline \multicolumn{1}{|c|}{ AUTOR } & \multicolumn{1}{|c|}{ DIMENSIONES } & \multicolumn{1}{c|}{ SUBDIMENSIONES } \\
\hline \multirow{4}{*}{ Sellito et al. (2003) } & \multirow{2}{*}{ Información } & Información General \\
\cline { 2 - 3 } & & Información de Productos \\
\cline { 2 - 3 } & Orden y Ventas & \\
\cline { 2 - 3 } & Comunidad & \\
\hline \multirow{4}{*}{ Murphy et al (2005) } & Popularidad /Visibilidad & \\
\cline { 2 - 3 } & & \\
\cline { 2 - 3 } & \multirow{4}{*}{ Características } & Información de Contactos Básica \\
\cline { 2 - 3 } & & Información Visual \\
\cline { 2 - 3 } & & Información Social \\
\cline { 2 - 3 } & Navegabilidad & Información Virtual \\
\hline & Marketing Relacional & \\
\cline { 2 - 3 } & Ventas & \\
\hline
\end{tabular}

Cuadro 2. Dimensiones de Efectividad de las Webs de las Bodegas. Fuente: Elaboración Propia.

Por lo tanto, tomando como referencia los estudios realizados por Hashim et al. (2007), Shegg et al. (2002), Sellito et al. (2003), y Murphy et al. (2005), se propone como ámbito de estudio el esquema reflejado en el Cuadro 3. De esta manera, se pretende determinar las características de las webs analizadas así como su orientación principal.
Así, la primera dimensión "Información y Procesos", es similar a la empleada por Hashim et al. (2007), y a "Servicios y Procesos" de Schegg et al. (2002), incluyendo algunos elementos de las dimensiones "Información” y "Orden y Ventas" (Sellito et al., 2003), y de "Ventas", "Información Básica", "Información Visual" e "Información Virtual" (Murphy et al., 2005). 
Por lo tanto, esta dimensión engloba la información de contacto de la empresa, la información general de la misma (presentación, noticias, fotos, videos, etc.), de sus productos, servicios y actividades, así como la posibilidad de realizar compras. Es decir, incluye todo lo necesario para que el cliente contacte con la empresa, obtenga información de la misma, y adquiera sus bienes y/o servicios (Schegg et al., 2002).

La segunda dimensión, "Creación de Valor", se basa en "Links Externos", "Información de la Región" (Schegg et al., 2002) e "Información de Viajes" (Hashim et al., 2007). Así, esta dimensión comprende toda la información adicional que se le brinda al cliente con el objetivo de completar la oferta turística y mejorar la experiencia del viaje. Es importante destacar que para conseguir el éxito en el desarrollo del turismo del vino debe ofrecerse algo más que viñedos y bodegas, siendo necesaria la oferta de atracciones adicionales, como alta cocina, experiencias culturales y buenas opciones de alojamiento (Getz et al., 2008). Por lo tanto, es importante incluir esta información en las páginas.

La tercera dimensión, "Construcción de Relaciones", se basa en las dimensiones "Relación con el Cliente" (Schegg et al., 2002), "Comunidad" (Sellito et al., 2003), "Marketing Relacional" (Murphy et al., 2005) y "Relaciones" (Hashim et al., 2007). Por lo tanto, comprende las herramientas de marketing relacional dirigidas a lograr la comunicación y la interacción con el cliente y la personalización de los servicios así como las herramientas de marketing viral que permiten al cliente compartir con sus contactos. Esta dimensión refleja el grado de evolución de la web en su interactividad (Murphy et al., 2005). Así, como ejemplos de marketing relacional on-line pueden citarse el ofrecer un perfil personal basado en las preferencias del cliente, invitar a la realización de comentarios en un libro de visitas
(Gilbert et al., 1999), o enviar un newsletter para mantener el contacto con los clientes (O'Neil, Charters, 2000). Como ejemplos de marketing viral pueden nombrarse el sugerir al usuario que recomiende la página $\circ$ envíe postales a sus contactos (Kirby, Mardensen, 2005).

La dimensión "Creación de Confianza" se basa en el apartado del mismo nombre propuesto por Schegg et al. (2002), en "Confianza" de Hashim et al. (2007) y en "Información de Confianza" de Murphy et al. (2005). La literatura especializada ha discutido el rol de la confianza en la creación y construcción de relaciones exitosas con los clientes (Bauer et al., 2000; Peppers et al., 200I; Wang et al., 2000). Los links externos, Copyright y fecha de última actualización incentivan la confianza en el sitio (Nielsen, 2000), y la marca en el dominio (ejemplo marca.com o marca.es) ayuda a construir valor de marca y aportar confianza (Hanson, 2000; Murphy et al., 2003). Elementos como la seguridad, la credibilidad y la continuidad aumentan la confianza en la empresa y fomentan la lealtad del cliente (Schegg et al., 2002).

Finalmente, la quinta dimensión "Diseño y Usabilidad" es similar a la propuesta por Hashim et al. (2007) y a "Navegabilidad de la Web" de Murphy et al. (2005). La navegabilidad de la web refleja el grado de desarrollo de la página en cuanto a interactividad e información. No tiene sentido ofrecer información si ésta no es fácil de encontrar por el usuario (Murphy et al., 2005). Bellman y Rossittier (2004) sugieren que la navegabilidad de la web se relaciona directamente con las actitudes positivas hacia el sitio y hacia la marca. Así, para mejorar la misma, algunos autores recomiendan incluir un mapa del sitio a visitar, preguntas frecuentes (FAQs) y función interactiva de búsqueda (Nielsen, 2000; Nysveen et al., 2002; Veen, 2000; Palmer, 2002).

\begin{tabular}{|c|c|c|c|}
\hline DIMENSIÓN & SUBDIMENSIÓN & & ITEMS \\
\hline \multirow{2}{*}{$\begin{array}{l}\text { Información } \\
\text { y Procesos }\end{array}$} & $\begin{array}{l}\text { Información de } \\
\text { Contacto }\end{array}$ & $\begin{array}{ll}\text { - } & \text { E-mail } \\
\text { - } & \text { Dirección física } \\
\text { - } & \text { Teléfono }\end{array}$ & $\begin{array}{ll}\text { - } & \text { Fax } \\
\text { - } & \text { Mapa }\end{array}$ \\
\hline & $\begin{array}{l}\text { Presentación de } \\
\text { la Empresa }\end{array}$ & $\begin{array}{l}\text { - Información sobre el } \\
\text { Negocio } \\
\text { - Días y horarios de } \\
\text { apertura }\end{array}$ & $\begin{array}{l}\text { - } \text { Fotos de la Finca } \\
\text { - Descargables }\end{array}$ \\
\hline
\end{tabular}




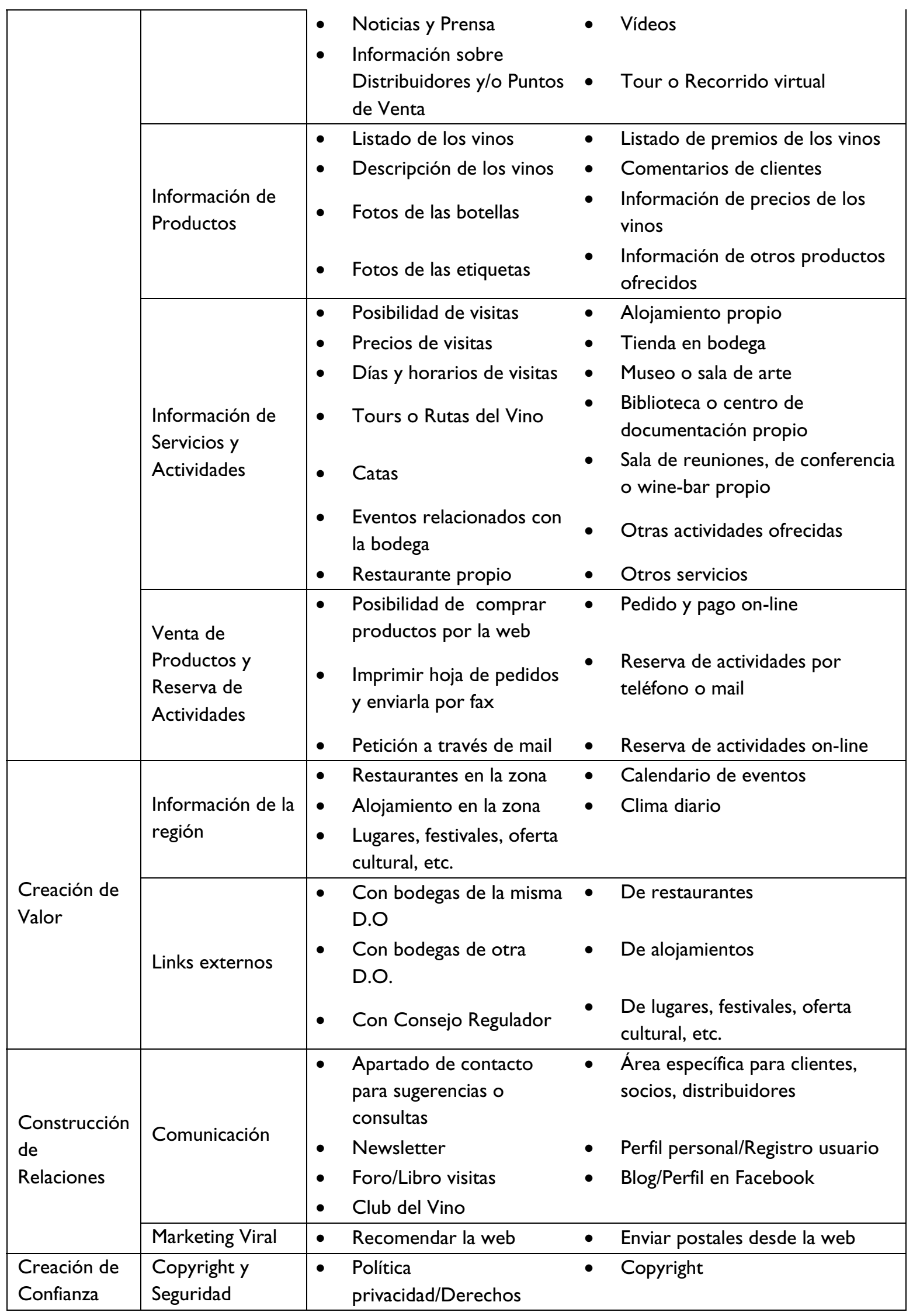




\begin{tabular}{|c|c|c|c|}
\hline & & Reservados/Aviso Legal & \\
\hline & $\begin{array}{l}\text { Temporalidad y } \\
\text { Marca }\end{array}$ & $\begin{array}{l}\text { - Fecha actualización web } \\
\text { - Dominio } \\
\text { marca.com/marca.net } \\
\text { - Dominio marca.com.es/ } \\
\text { marca.es } \\
\end{array}$ & $\begin{array}{l}\text { - Otro dominio } \\
\text { - E-mail propio } \\
\text { - Web e-mail }\end{array}$ \\
\hline $\begin{array}{l}\text { Diseño y } \\
\text { Usabilidad }\end{array}$ & Navegabilidad & $\begin{array}{l}\text { - Número de idiomas } \\
\text { - Iisponibles } \\
\text { - } \quad \text { Idiomas que ofrece } \\
\text { - Mapa del sitio }\end{array}$ & $\begin{array}{l}\text { - } \text { Función de búsqueda } \\
\text { - } \quad \text { Preguntas frecuentes }\end{array}$ \\
\hline
\end{tabular}

Cuadro 3. Dimensiones Propuestas para la Efectividad de las Webs de las Bodegas.

\begin{tabular}{|l|c|c|c|c|c|c|}
\cline { 2 - 7 } \multicolumn{1}{c|}{} & \multicolumn{2}{c|}{ La Rioja } & \multicolumn{2}{c|}{ Aragón } & \multicolumn{2}{c|}{ Total } \\
\cline { 2 - 8 } \multicolumn{1}{c|}{} & Frec. & $\%$ & Frec. & $\%$ & Frec. & $\%$ \\
\hline Posee página web en funcionamiento & 198 & 33,5 & 61 & 60,4 & 259 & 37,4 \\
\hline No posee página web & 379 & 64,1 & 40 & 39,6 & 419 & 60,5 \\
\hline $\begin{array}{l}\text { Web en construcción o fuera de } \\
\text { funcionamiento }\end{array}$ & 14 & 2,4 & 0 & 0,0 & 14 & 2,0 \\
\hline Total & 591 & 100,0 & 101 & 100,0 & 692 & 100,0 \\
\hline
\end{tabular}

Tabla I. Páginas Webs en La Rioja y Aragón.

\section{Análisis y Resultados}

\section{Base de Datos}

La información analizada proviene de las webs de las bodegas existentes en las dos regiones consideradas, La Rioja y Aragón. Para crear la base de datos fue necesario elaborar, en primer lugar, un listado de todas las bodegas integrantes de cada una de las Denominaciones de Origen situadas en dichas zonas. Concretamente, existen 4 Denominaciones de Origen en Aragón (Somontano, Cariñena, Campo de Borja y Calatayud) y I en La Rioja ${ }^{4}$. Así, tras identificar las I0I bodegas presentes en Aragón y las 59I en La Rioja, se buscó si poseían o no página web en la $\operatorname{red}^{5}$. La búsqueda realizada mostró que un $37,4 \%$ de las bodegas

4 Para ello se consultaron las páginas web de los Consejos Reguladores de cada una de ellas: Somontano (www.dosomontano.com), Cariñena (www.docarinena.es), Campo de Borja (www.campodeborja.com), Calatayud (www.docalatayud.com) y La Rioja (www.riojawine.com).

${ }_{5}$ Para conocer si las bodegas poseen páginas web se utilizó el motor de búsqueda Google (www.google.es) ya que los datos analizadas poseen $w^{6} b^{6}$. Una vez localizados las 259 webs se comprobó la existencia de los ítems del esquema propuesto en el Cuadro 3. El proceso de elaboración de la base de datos se realizó en el período de enero a septiembre de 2009.

Una vez elaborada la base de datos, se realizó, en primer lugar, un análisis descriptivo de la información obtenida. Tras ello, se llevó a cabo un análisis Cluster con el objetivo de determinar la existencia de grupos de webs en función de su principal orientación.

\section{Análisis Descriptivo}

Como se observa en la Tabla I, de las 59I bodegas que integran la Denominación de Origen de La Rioja, tan solo el 33,5\% (198) poseen página web en funcionamiento, siendo este porcentaje superior en las $10 \mathrm{I}$ bodegas de Aragón, ya que el 60,4\% (6I) de ellas posee web.

Para describir las dimensiones de efectividad de las webs analizadas y determinar las diferencias existentes entre

proveídos por las páginas de los Consejos Reguladores se encuentran desactualizados.

${ }^{6} \mathrm{O}$ muestran su página web en Google. 
los dos destinos bajo estudio, se realizan las correspondientes tablas de contingencia, y se analizan sus residuos tipificados corregidos y las Chi-Cuadrado. Los resultados obtenidos se muestran en las tablas siguientes.

Dimensión I: Información y Procesos: Como se muestra en la Tabla 2 no emergen diferencias significativas en la mayoría de las subdimensiones analizadas. Así, en lo relativo a "Información de Contacto" la práctica totalidad de las páginas proporcionan información sobre su e-mail, dirección física, teléfono y fax, y mapa; en "Presentación de la Empresa" sólo emergen diferencias en la información sobre días y horarios de apertura (siendo mayor en Aragón) y en la presencia de fotos de la finca $y$ descargables (mayor en La Rioja); en
"Información de Productos" únicamente se detecta una diferencia significativamente superior en La Rioja en lo que respecta al listado de vinos; en "Venta de Productos y Reserva de Actividades" se detecta una presencia ligeramente superior de la posibilidad de reservar actividades por mail, teléfono y on-line en las bodegas de La Rioja; y en "Información de Servicios y Actividades" se detecta una mayor información en las webs riojanas sobre los aspectos relacionados directamente con las visitas a la bodega (posibilidad de realizar visitas, precios y días de las mismas y sobre la oferta de actividades de catas). En el resto de variables (restaurantes, alojamiento, tiendas, museos, bibliotecas, vinoterapia, etc.) no existen diferencias significativas.

\begin{tabular}{|c|c|c|c|c|}
\hline & \\
\hline & La Rioja (\%) & Aragón (\%) & Total (\%) & Sig. \\
\hline \multicolumn{5}{|l|}{ I.I Información de contacto } \\
\hline E-mail & 100,0 & 100,0 & 100,0 & \\
\hline Dirección física & 100,0 & 98,4 & 99,6 & \\
\hline Teléfono & 100,0 & 98,4 & 99,6 & \\
\hline Fax & 97,0 & 95,1 & 96,5 & \\
\hline Mapa & 77,8 & 68,9 & 75,7 & \\
\hline \multicolumn{5}{|l|}{ I.2 Presentación de la Empresa } \\
\hline Información sobre el negocio & 94,9 & 93,4 & 94,6 & \\
\hline Días y horarios de apertura & 6,1 & 14,8 & 8,1 & ** \\
\hline Noticias y prensa & 55,6 & 49,2 & $54, I$ & \\
\hline $\begin{array}{l}\text { Información de distribuidores y/o puntos de } \\
\text { venta físicos }\end{array}$ & 8,6 & II,5 & 9,3 & \\
\hline Fotos de la finca & 97,5 & 88,5 & 95,4 & $* *$ \\
\hline Descargables & 38,4 & 26,2 & 35,5 & $*$ \\
\hline Fichas de cata & 33,3 & 16,4 & 29,3 & ** \\
\hline Folletos, catálogos & 4,5 & 4,9 & 4,6 & \\
\hline Publicidad, prensa & 3,5 & 1,6 & 3,1 & \\
\hline Fondo, protector de pantalla & 1,0 & 0,0 & 0,8 & \\
\hline Revista, boletín & 1,5 & 0,0 & 1,2 & \\
\hline Fotos & 1,5 & 1,6 & 1,5 & \\
\hline Mapa & 1,0 & 0,0 & 0,8 & \\
\hline Itinerarios visitas o rutas & 3,5 & 1,6 & 3,1 & \\
\hline Otros & 1,5 & 6,6 & 2,7 & $*$ \\
\hline Videos & 7,1 & 11,5 & 8,1 & \\
\hline Tour o recorrido virtual & 12,1 & 6,6 & 10,8 & \\
\hline \multicolumn{5}{|l|}{ I.3 Información de productos } \\
\hline Listado de los vinos & 97,5 & 90,2 & 95,8 & *** \\
\hline Descripción de los vinos & 92,9 & 91,8 & 92,7 & \\
\hline
\end{tabular}




\begin{tabular}{|c|c|c|c|c|}
\hline Fotos de las botellas de vinos & 96,0 & 98,4 & 96,5 & \\
\hline Fotos de las etiquetas & 98,0 & 98,4 & 98,1 & \\
\hline Listado de premios de los vinos & 32,8 & $4 I, 0$ & 34,7 & \\
\hline Comentarios de clientes & 2,5 & 1,6 & 2,3 & \\
\hline Información de precios de los vinos & 17,2 & 21,3 & 18,1 & \\
\hline Información de otros productos ofrecidos & 7,1 & 6,6 & 6,9 & \\
\hline \multicolumn{5}{|l|}{ I.4 Información de servicios y actividades } \\
\hline Información sobre la posibilidad de visita & $4 I, 9$ & $3 I, I$ & 39,4 & $*$ \\
\hline Información sobre precios de la visita & 15,7 & 3,3 & 12,7 & ** \\
\hline \multicolumn{5}{|l|}{ Precio de la visita } \\
\hline Gratis & 1,5 & 0,0 & 1,2 & \\
\hline 2 a 6 euros & $\mathrm{II}, \mathrm{I}$ & 1,6 & 8,9 & \\
\hline 7 a 15 euros & 6,1 & 1,6 & 5,0 & \\
\hline 16 euros o mas & 1,5 & 0,0 & 1,2 & \\
\hline Días y horarios de visita & 23,7 & $\mathrm{II}, 5$ & 20,8 & *** \\
\hline Visitas días de semana & 21,7 & $\mathrm{II}, 5$ & 19,3 & $*$ \\
\hline Visitas fin de semana & 19,7 & $\mathrm{II}, 5$ & 17,8 & $*$ \\
\hline Información sobre tours o rutas del vino & $\mathrm{II}, \mathrm{I}$ & 8,2 & 10,4 & \\
\hline Información sobre catas & 23,2 & $1 \mathrm{II}, 5$ & 20,5 & ** \\
\hline $\begin{array}{l}\text { Información sobre eventos organizados por } \\
\text { la bodega }\end{array}$ & 7,1 & 6,6 & 6,9 & \\
\hline Información sobre restaurante propio & 16,7 & 9,8 & 15,1 & \\
\hline Información sobre alojamiento propio & 3,0 & 0,0 & 2,3 & \\
\hline Información sobre tienda en la bodega & 10,1 & 14,8 & $1 \mathrm{II}, 2$ & \\
\hline Información sobre museo propio & 2,0 & 4,9 & 3,5 & \\
\hline $\begin{array}{l}\text { Información sobre biblioteca o centro de } \\
\text { documentación propio }\end{array}$ & 1,5 & 1,6 & 1,5 & \\
\hline $\begin{array}{l}\text { Información sobre sala de reuniones, de } \\
\text { conferencias o wine-bar propio }\end{array}$ & 4,5 & 6,6 & 5,0 & \\
\hline $\begin{array}{l}\text { Otras actividades ofrecidas: spa vinoterapia, } \\
\text { paseos en globo }\end{array}$ & 2,0 & 0,0 & 1,5 & \\
\hline $\begin{array}{l}\text { Otros servicios: consulta a enólogo, } \\
\text { personalización de vinos }\end{array}$ & 2,5 & 0,0 & 1,9 & \\
\hline \multicolumn{5}{|l|}{ I.5 Venta de productos y reserva de actividades } \\
\hline $\begin{array}{l}\text { Posibilidad de comprar productos por la } \\
\text { web }\end{array}$ & 25,3 & 24,6 & 25,1 & \\
\hline Imprimir hoja de pedidos y envío por fax & 0,0 & 0,0 & 0,0 & \\
\hline Petición a través de un e-mail & 5,1 & $\mathrm{I}, 6$ & 4,2 & \\
\hline Pedido y pago on-line & 20,2 & 23,0 & 21,2 & \\
\hline $\begin{array}{l}\text { Reserva de actividades por teléfono o e- } \\
\text { mail }\end{array}$ & 36,9 & 24,6 & 34,0 & $*$ \\
\hline Reserva de actividades on-line & 11,6 & 3,3 & 9,7 & ** \\
\hline
\end{tabular}

Diferencias significativas La Rioja/Aragón según estadístico Chi-Cuadrado*0,10; ** 0,5; *** 0,0I.

Tabla 2. Descripción Webs de La Rioja y Aragón (Dimensión I: Información y Procesos). 
Dimensión 2: Creación de Valor, recoge aspectos relacionados con la información sobre la región de las bodegas y con la presencia de links externos. Así, y como se observa en la Tabla 3, en lo relacionado con el primer aspecto no se detectan diferencias significativas entre las páginas de los dos destinos. Aunque su presencia es escasa en las webs, la información que se suele proporcionar está relacionada con los restaurantes y alojamientos de la zona, el calendario de eventos, el clima o la oferta cultural y turística de la región. En lo relativo a Links Externos, se observa que las bodegas de La Rioja presentan links con otras bodegas en mayor proporción que las de Aragón, no existiendo diferencias en la existencia de links a restaurantes, alojamientos y oferta cultural y turística de la zona.

\begin{tabular}{|c|c|c|c|c|}
\hline & La Rioja (\%) & Aragón (\%) & Total (\%) & Sig. \\
\hline \multicolumn{5}{|l|}{ 2.I Información de la región } \\
\hline Información de restaurantes de la zona & 4,5 & 1,6 & 3,9 & \\
\hline Información de alojamientos de la zona & 5,1 & 6,6 & 5,4 & \\
\hline $\begin{array}{l}\text { Información de lugares, festivales y/u oferta } \\
\text { cultural o turística de la zona }\end{array}$ & 10,6 & $|3|$, & $\mathrm{II}, 2$ & \\
\hline Calendario de eventos & 0,5 & 0,0 & 0,4 & \\
\hline Información del clima del día & 1,0 & 1,6 & 1,2 & \\
\hline \multicolumn{5}{|l|}{ 2.2 Links externos } \\
\hline Links con otras bodegas de la misma D.O. & 10,6 & 3,3 & 8,9 & $*$ \\
\hline Links con otras bodegas de otra D.O. & 10,6 & 0,0 & 8,1 & $* *$ \\
\hline $\begin{array}{l}\text { Links con Consejo Regulador de DO u otras } \\
\text { asociaciones }\end{array}$ & 19,2 & $|3|$, & 17,8 & \\
\hline Links de restaurantes de la zona & 3,5 & 1,6 & 3,1 & \\
\hline Links con alojamientos de la zona & 5,6 & 6,6 & 5,8 & \\
\hline $\begin{array}{l}\text { Links de lugares, festivales y/u oferta cultural } \\
\text { o turística de la zona }\end{array}$ & 6,1 & 3,3 & 5,4 & \\
\hline
\end{tabular}

Diferencias significativas La Rioja/Aragón según estadístico Chi-Cuadrado * 0,10; ** 0,5; *** 0,01.

Tabla 3. Descripción Webs de La Rioja y Aragón (Dimensión 2: Creación de Valor).

Dimensión 3: Construcción de Relaciones, a partir del marketing relacional y viral. En relación a las herramientas que utilizan las bodegas para la comunicación e interacción con sus clientes, el método más frecuente, como se observa en la Tabla 4, es el apartado de "Contacto" para el envío de consultas o sugerencias, aunque no se detectan diferencias entre La Rioja y Aragón. Esto denota el carácter pasivo de las bodegas, ya que sólo invitan a los clientes a que inicien ellos la comunicación. Emergen diferencias significativas en los Clubs del Vino, existencia de un área específica para clientes o registro personal/Perfil del usuario. Así, los Clubs del Vino están más presentes en las webs de
La Rioja aunque la gran mayoría de estos Clubs se encuentran lejos de formar una "comunidad virtual" ya que sólo se invita a asociarse al mismo. Por contra, las webs aragonesas poseen una mayor presencia de áreas específicas para clientes y registro de usuarios. En relación al marketing viral se analizan dos actividades, emergiendo diferencias significativas en la recomendación de la página web, opción presente en algunas webs de La Rioja y en ninguna de Aragón. Destacar que la posibilidad de enviar postales desde la web es una opción prácticamente inexistente en los destinos analizados. 


\begin{tabular}{|l|c|c|c|c|}
\cline { 2 - 5 } \multicolumn{1}{c|}{} & La Rioja (\%) & Aragón (\%) & Total (\%) & Sig. \\
\hline 3.I Comunicación & & & & \\
\hline $\begin{array}{l}\text { Apartado de "Contacto" para enviar } \\
\text { consultas o sugerencias }\end{array}$ & 44,9 & 42,6 & 44,4 & \\
\hline Newsletter & 13,6 & 9,8 & 12,7 & \\
\hline Foro / Libro de visitas & 3,0 & 1,6 & 2,7 & \\
\hline Club del Vino & 22,2 & 0,0 & 17,0 & $* * *$ \\
\hline Área para clientes, socios o distribuidores & 3,0 & 8,2 & 4,2 & $*$ \\
\hline Perfil personal / Registro de usuario & 9,1 & 16,4 & 10,8 & $*$ \\
\hline Posee Blog o Perfil en Facebook & 2,5 & 0,0 & 1,9 & \\
\hline 3.2 Marketing viral & & & & \\
\hline Recomendar la web & 4,5 & 0,0 & 3,5 & $*$ \\
\hline Enviar postales desde la página & 0,5 & 0,0 & 0,4 & \\
\hline
\end{tabular}

Diferencias significativas La Rioja/Aragón según estadístico Chi-Cuadrado* 0,I0; ** 0,5; *** 0,0I.

Tabla 4. Descripción Webs de La Rioja y Aragón (Dimensión 3: Construcción de Relaciones).

Dimensión 4: Creación de Confianza. Esta dimensión recoge los aspectos relacionados con el Copyright, la seguridad, la temporalidad y la marca, no emergiendo diferencias significativas en ninguna de las variables analizadas (Tabla 5). Se puede destacar que las políticas de privacidad están presentes en un tercio de las páginas analizadas, descendiendo este porcentaje en la presencia de Copyright. En cuanto a la Temporalidad y Marca se observa la ausencia de la indicación de la fecha de última actualización de las webs, en la práctica totalidad de las páginas aparece marca.com, marca.net $\circ$ marca.es. Finalmente, en relación a la dirección de correo electrónico, más del $80 \%$ posee una dirección propia (...@marca), mientras que el porcentaje restante utiliza un web mail u otro servidor no propio (ej...@hotmail).

\begin{tabular}{|l|c|c|c|c|}
\cline { 2 - 5 } \multicolumn{1}{c|}{} & La Rioja (\%) & Aragón (\%) & Total (\%) & Sig. \\
\hline 4.I Copyright y seguridad & & & & \\
\hline $\begin{array}{l}\text { Política de privacidad /Derechos reservados } \\
\text { / Aviso legal }\end{array}$ & 36,9 & 31,1 & 35,5 & \\
\hline Copyright & 21,2 & 29,5 & 23,2 & \\
\hline 4.2 Temporalidad y marca & & & & \\
\hline Fecha de ultima actualización de la web & 0,0 & 0,0 & 0,0 & \\
\hline Dominio: marca.com / marca.net & 84,3 & 85,2 & 84,6 & \\
\hline Dominio: marca.com.es / marca.es & 15,2 & 11,5 & 14,3 & \\
\hline Otro dominio & 0,5 & 0,0 & 0,4 & \\
\hline E-mail propio / ...@marca & 83,8 & 82,0 & 83,4 & \\
\hline Web e-mail / ...@otro & 16,2 & 14,8 & 15,8 & \\
\hline & & & & \\
\hline
\end{tabular}

Diferencias significativas La Rioja/Aragón según estadístico Chi-Cuadrado * 0,I0; ** 0,5; *** 0,0I.

Tabla 5. Descripción Webs de La Rioja y Aragón (Dimensión 4: Creación de Confianza).

Dimensión 5: Diseño y Usabilidad (Tabla 6). En los dos destinos analizados, la mayor parte de las páginas está disponible en español e inglés. Emergen diferencias significativas en cuanto al uso de mapa del sitio, que lo 
utilizan más las bodegas riojanas que las aragonesas. Las funciones de búsqueda y el apartado de "Preguntas
Frecuentes" están escasamente presentes en todas las páginas.

\begin{tabular}{|c|c|c|c|c|}
\hline & La Rioja (\%) & Aragón (\%) & Total (\%) & Sig. \\
\hline \multicolumn{5}{|l|}{ 5.I Navegabilidad } \\
\hline \multicolumn{5}{|l|}{ Cantidad de idiomas disponibles } \\
\hline Solo español & 22,2 & 14,8 & 20,5 & \\
\hline Español e ingles & 57,6 & 55,7 & 57,1 & \\
\hline 3 a 5 idiomas & 20,2 & 24,6 & 21,2 & \\
\hline 6 o mas idiomas & 0,0 & 3,3 & 0,8 & \\
\hline Webs disponibles en ingles & 77,8 & 83,6 & 79,2 & $*$ \\
\hline Webs disponibles en alemán & 15,7 & 18,0 & 16,2 & \\
\hline Webs disponibles en francés & 7,6 & 18,0 & 10,0 & $* *$ \\
\hline Webs disponibles en japonés & $\mathrm{I}, 5$ & 6,6 & 2,7 & \\
\hline Webs disponibles en chino & $\mathrm{I}, 0$ & 4,9 & 1,9 & $*$ \\
\hline $\begin{array}{l}\text { Webs disponibles en euskera, catalán } \\
\text { o valenciano }\end{array}$ & 3,5 & 0,0 & 2,7 & \\
\hline $\begin{array}{l}\text { Webs disponibles en otros idiomas } \\
\text { (italiano, ruso, holandés, danés o } \\
\text { polaco) }\end{array}$ & $\mathrm{I}, 5$ & 4,9 & 2,3 & \\
\hline Mapa del sitio & $I I, I$ & 1,6 & 8,9 & ** \\
\hline Función de búsqueda & 8,6 & 9,8 & 8,9 & \\
\hline Preguntas frecuentes (FAQs) & 1,5 & 0,0 & $\mathrm{I}, 2$ & \\
\hline
\end{tabular}

Diferencias significativas La Rioja/Aragón según estadístico Chi-Cuadrado * 0,10; ** 0,5; *** 0,0I.

Tabla 6. Descripción Webs de La Rioja y Aragón (Dimensión 5: Diseño y Usabilidad).

\section{Análisis Cluster}

Con el objetivo de detectar la existencia de grupos de páginas con distintos perfiles, con independencia de la Denominación de Origen o región que las emplee, se procede a la realización de un análisis Cluster. Este análisis permite detectar la existencia de grupos o conglomerados, lo más homogéneos en sí y lo más heterogéneos entre sí con respecto a la distribución de las variables analizadas (Hair et al., 2000). De los posibles algoritmos aplicables se emplea el método Ward, que permite minimizar las diferencias dentro del cluster, evitando problemas con el encadenamiento de las observaciones y obtiene la mínima varianza entre observaciones, y la distancia euclídea al cuadrado. Para analizar la significatividad de las diferencias entre los grupos se realizó el correspondiente ANOVA, aplicándose el test de Duncan.

Los resultados obtenidos, mostrados en la Tabla 7, ponen de manifiesto la presencia de tres grupos de webs con diferentes orientaciones: a la venta on-line, al desarrollo del turismo del vino y proveer solo información básica.

El primero de los grupos detectados, orientado a la Venta On-Line de sus productos (GI), es el menos numeroso ya que está integrado por las webs de 18 bodegas. Las diferencias detectadas ponen de manifiesto que la práctica mayoría de las bodegas de este grupo $(94,4 \%)$ vende sus productos on-line $y$, en la mayor parte de los casos $(88,9 \%)$, la venta y el pago se realizan totalmente on-line. Además, en este grupo se detecta la mayor presencia de las dos actividades de Marketing viral analizadas, utilizando como herramienta de comunicación principal el apartado de "Contacto" (83,3\%). Otro rasgo a destacar es que estas webs presentan las mayores tasas de uso de Registro de usuario y de la herramienta de Función de búsqueda. Estos dos elementos están claramente relacionados con la venta on-line, ya que en muchas de las webs se requiere registrarse como cliente previamente a la transacción, estando asociada la función de búsqueda sólo a la búsqueda 
de productos. Por otra parte, también se detectan diferencias en la mayor disponibilidad de información sobre los precios de los vinos y en la presencia de links con el Consejo Regulador de la Denominaciones de Origen y otras asociaciones.

El segundo de los grupos (G2) está integrado por 54 webs, siendo éstas las más completas, ya que aportan mayor cantidad y calidad de información. Esta información no se centra sólo en la propia bodega, sus productos, servicios y actividades, sino también en la oferta cultural y turística de la zona. Por lo tanto, se observa una tendencia al desarrollo del Enoturismo. Las diferencias estadísticamente significativas detectadas con los dos grupos restantes sirven para establecer el perfil de este grupo de webs. Así, se observa que casi la totalidad de las webs $(96,3 \%)$ informa sobre la posibilidad de visitar la bodega, indicando la mayoría de ellas detalles sobre los precios, días y horarios disponibles. El 44,4\% permite realizar la reserva de la visita on-line, y el $85,2 \%$ sugiere realizarla por teléfono $\circ$ a través del e-mail. Este grupo también se distingue por proporcionar información sobre tours, rutas del vino, catas y eventos organizados por la bodega y por ofrecer servicios adicionales como la consulta a su enólogo - la personalización de vinos para regalos. Además, estas bodegas muestran el mayor interés en proveer información acerca de la oferta turística y cultural de la zona (25,9\%), así como de links a otras páginas sobre estos temas $(14,8 \%)$. En cuanto a la relación con sus clientes, se detecta el uso de herramientas más sofisticadas que permitan un contacto más personal y comprometido con el cliente, como es el caso de los Clubs del Vino (55,6\%).
Finalmente, la totalidad de estas bodegas poseen dirección de e-mail propia (...@marca), y presentan los porcentajes más elevados de links con bodegas de otras D.O. y de mapa del sitio $(27,8 \%)$. Por tanto, como ya se ha indicado, constituyen las webs más completas y complejas.

Finalmente, emerge el grupo más numeroso (G3), integrado por 187 webs, en el que se encuentran las bodegas que únicamente emplean esta herramienta para ofrecer información básica sobre ellas. Estas webs sólo ofrecen datos de contacto de la empresa, información del negocio y de sus productos, presentando los menores índices en la posesión de la gran mayoría de las variables analizadas. Únicamente emergen diferencias significativas en la inclusión de noticias y notas de prensa, videos, tour virtual, descargables, información de precios de los vinos y museo propio, que es menor que en los otros dos grupos. También presentan los menores índices de venta on-line y de publicación de sus Políticas de privacidad, de uso de Newsletter, de Registro de usuario y de existencia de un área específica para clientes o socios.

Además de las variables indicadas en el Cuadro 3 , se analizó la existencia de diferencias significativas entre los tres grupos de webs detectados según la Comunidad en la que estuviesen situadas las bodegas. Los resultados obtenidos permiten afirmar que el Grupo 2, orientado al desarrollo del enoturismo, está compuesto mayoritariamente por bodegas de La Rioja, mientras que el Grupo 3, centrado en la información básica, está integrado fundamentalmente por bodegas de Aragón.

\begin{tabular}{|l|c|c|c|c|c|}
\cline { 2 - 6 } \multicolumn{1}{c|}{} & GI (\%) & G2 (\%) & G3 (\%) & Dif. & Sig. \\
\hline I INFORMACIÓN Y PROCESOS & & & & & \\
\hline I.I Información de contacto & & & & & \\
\hline E-mail & 100,0 & 100,0 & 98,4 & & \\
\hline Dirección física & 100,0 & 100,0 & 99,5 & & \\
\hline Teléfono & 100,0 & 100,0 & 99,5 & & \\
\hline Fax & 100,0 & 100,0 & 95,2 & & \\
\hline Mapa & 88,9 & 85,2 & 71,7 & & \\
\hline I.2 Presentación de la Empresa & & & & & \\
\hline Información sobre el negocio & 94,4 & 98,1 & 93,6 & & \\
\hline Días y horarios de apertura & 5,6 & 18,5 & 5,3 & $1-2,2-3$ & $* *$ \\
\hline Noticias y prensa & 77,8 & 94,4 & 40,1 & $1-3,2-3$ & $* * *$ \\
\hline Información de distribuidores y/o puntos de & & & & & \\
\hline venta físicos & 11,1 & 16,7 & 7,0 & & \\
\hline Fotos de la finca & 88,9 & 100,0 & 94,7 & & \\
\hline Descargables & 50,0 & 63,0 & 26,2 & $1-3,2-3$ & $* * *$ \\
\hline
\end{tabular}




\begin{tabular}{|c|c|c|c|c|c|}
\hline Videos & 27,8 & 20,4 & 2,7 & $1-3,2-3$ & **** \\
\hline Tour o recorrido virtual & 27,8 & 29,6 & 3,7 & $1-3,2-3$ & **** \\
\hline \multicolumn{6}{|l|}{ I.3 Información de productos } \\
\hline Listado de los vinos & 100,0 & 100,0 & 94,1 & & \\
\hline Descripción de los vinos & 94,4 & 96,3 & 91,4 & & \\
\hline Fotos de las botellas de vinos & 100,0 & 98,1 & 95,7 & & \\
\hline Fotos de las etiquetas & 100,0 & 98,1 & 97,9 & & \\
\hline Listado de premios de los vinos & 33,3 & 50,0 & 30,5 & & \\
\hline Comentarios de clientes & $\mathrm{II}, \mathrm{I}$ & 5,6 & 0,5 & $\mathrm{I}-3$. & ** \\
\hline Información de precios de los vinos & 83,3 & 35,2 & 7,0 & $\begin{array}{c}\mathrm{I}-2, \mathrm{I}-3 \\
2-3\end{array}$ & $* * *$ \\
\hline Información de otros productos ofrecidos & 16,7 & $\mathrm{II}, \mathrm{I}$ & 4,8 & & \\
\hline \multicolumn{6}{|l|}{ I.4 Información de servicios y actividades } \\
\hline Información sobre la posibilidad de visita & 27,8 & 96,3 & 24,1 & $\mathrm{I}-2,2-3$ & **** \\
\hline Información sobre precios de la visita & 0,0 & 53,7 & 2,1 & $\mathrm{I}-2,2-3$ & $* * *$ \\
\hline Días y horarios de visita & 5,6 & 66,7 & 9,1 & $\mathrm{I}-2,2-3$ & **** \\
\hline Visitas días de semana & 5,6 & 63,0 & 8,0 & $\mathrm{I}-2,2-3$ & $* * *$ \\
\hline Visitas fin de semana & 5,6 & 55,6 & 8,0 & $\mathrm{I}-2,2-3$ & **** \\
\hline Información sobre tours o rutas del vino & 0,0 & 40,7 & 2,7 & $\mathrm{I}-2,2-3$ & **** \\
\hline Información sobre catas & 5,6 & 68,5 & 8,6 & $1-2,2-3$ & **** \\
\hline $\begin{array}{l}\text { Información sobre eventos organizados por la } \\
\text { bodega }\end{array}$ & 0,0 & 29,6 & $\mathrm{I}, \mathrm{I}$ & $1-2,2-3$ & $* * *$ \\
\hline Información sobre restaurante propio & 22,2 & 31,5 & 9,6 & $2-3$. & ***k \\
\hline Información sobre alojamiento propio & 0,0 & 7,4 & $\mathrm{I}, \mathrm{I}$ & $\mathrm{I}-2$ & $* *$ \\
\hline Información sobre tienda en la bodega & 0,0 & 22,2 & 9,1 & $\mathrm{I}-2$. & ** \\
\hline Información sobre museo propio & $\mathrm{II}, \mathrm{I}$ & 9,3 & $\mathrm{I}, \mathrm{I}$ & $\mathrm{I}-3,2-3$ & ** \\
\hline $\begin{array}{l}\text { Información sobre biblioteca o centro de } \\
\text { documentación propio }\end{array}$ & 0,0 & 7,4 & 0,0 & $\mathrm{I}-2,2-3$ & $* * *$ \\
\hline $\begin{array}{l}\text { Información sobre sala de reuniones, de } \\
\text { conferencias o wine bar propio }\end{array}$ & 0,0 & 20,4 & $\mathrm{I}, \mathrm{I}$ & $1-2,2-3$ & $* * *$ \\
\hline $\begin{array}{l}\text { Otras actividades ofrecidas: spa vinoterapia, } \\
\text { paseos en globo }\end{array}$ & 0,0 & 5,6 & 0,5 & & \\
\hline $\begin{array}{l}\text { Otros servicios: consulta a enólogo, } \\
\text { personalización de vinos }\end{array}$ & 0,0 & 7,4 & 0,5 & $\mathrm{I}-2,2-3$ & $* *$ \\
\hline \multicolumn{6}{|l|}{ I.5 Venta de productos y reserva de actividades } \\
\hline Posibilidad de comprar productos por la web & 94,4 & 53,7 & 10,2 & $\begin{array}{c}\mathrm{I}-2, \mathrm{I}-3 \\
2-3\end{array}$ & $* * *$ \\
\hline Imprimir hoja de pedidos y envío por fax & 0,0 & 0,0 & 0,0 & & \\
\hline Petición a través de un e-mail & $\mathrm{II}, \mathrm{I}$ & $\mathrm{II}, \mathrm{I}$ & 1,6 & $\mathrm{I}-3,2-3$ & *** \\
\hline Pedido y pago on-line & 88,9 & 42,6 & 8,6 & $\begin{array}{c}1-2, I-3, \\
2-3\end{array}$ & $* * *$ \\
\hline Reserva de actividades por teléfono o e-mail & 11,1 & 85,2 & 21,4 & $\mathrm{I}-2,2-3$ & **** \\
\hline Reserva de actividades on-line & 5,6 & 44,4 & 0,0 & $\mathrm{I}-2,2-3$ & $* * *$ \\
\hline \multicolumn{6}{|l|}{2 CREACIÓN DE VALOR } \\
\hline \multicolumn{6}{|l|}{ 2.I Información de la región } \\
\hline Información de restaurantes de la zona & 5,6 & $\mathrm{II}, \mathrm{I}$ & 1,6 & $2-3$. & $* *$ \\
\hline
\end{tabular}




\begin{tabular}{|c|c|c|c|c|c|}
\hline Información de alojamientos de la zona & $\mathrm{II}, \mathrm{I}$ & 14,8 & 2,1 & $2-3$. & $* *$ \\
\hline $\begin{array}{l}\text { Información de lugares, festivales y/u oferta } \\
\text { cultural o turística de la zona }\end{array}$ & $\mathrm{II}, \mathrm{I}$ & 25,9 & 7,0 & $1-2,2-3$ & $* *$ \\
\hline Calendario de eventos & 0,0 & 1,9 & 0,0 & & \\
\hline Información del clima del día & 5,6 & 1,9 & 0,5 & & \\
\hline \multicolumn{6}{|l|}{ 2.2 Links externos } \\
\hline Links con otras bodegas de la misma D.O. & 5,6 & 16,7 & 7,0 & & \\
\hline Links con otras bodegas de otra D.O. & 5,6 & 20,4 & 4,8 & $\mathrm{I}-2,2-3$ & $* *$ \\
\hline $\begin{array}{l}\text { Links con Consejo Regulador de DO u otras } \\
\text { asociaciones }\end{array}$ & 50,0 & 27,8 & $1 \mathrm{I}, 8$ & $1-2, \mid-3$ & $* * *$ \\
\hline Links de restaurantes de la zona & 5,6 & 9,3 & $\mathrm{I}, \mathrm{I}$ & $2-3$ & ** \\
\hline Links con alojamientos de la zona & $\mathrm{II}, \mathrm{I}$ & 13,0 & 3,2 & & \\
\hline $\begin{array}{l}\text { Links de lugares, festivales y/u oferta cultural o } \\
\text { turística de la zona }\end{array}$ & 0,0 & 14,8 & 3,2 & $1-2,2-3$ & ** \\
\hline \multicolumn{6}{|l|}{3 CONSTRUCCIÓN DE RELACIONES } \\
\hline \multicolumn{6}{|l|}{ 3.I Comunicación } \\
\hline $\begin{array}{l}\text { Apartado de "Contacto" para enviar consultas } \\
\text { o sugerencias }\end{array}$ & 83,3 & 51,9 & 38,5 & I-2, I-3 & ** \\
\hline Newsletter & 22,2 & 33,3 & 5,9 & $\mathrm{I}-3,2-3$ & $* * *$ \\
\hline Foro / Libro de visitas & 5,6 & 5,6 & $\mathrm{I}, 6$ & & \\
\hline Club del Vino & $\mathrm{II}, \mathrm{I}$ & 55,6 & 6,4 & $\mathrm{I}-2,2-3$ & $* * *$ \\
\hline Área para clientes, socios o distribuidores & 16,7 & $I I, I$ & $\mathrm{I}, 6$ & $1-3,2-3$ & $* * *$ \\
\hline Perfil personal / Registro de usuario & 72,2 & 22,2 & 1,6 & $\begin{array}{c}\mathrm{I}-2, \mathrm{I}-3, \\
2-3\end{array}$ & $* * *$ \\
\hline Posee Blog o Perfil en Facebook & 5,6 & 3,7 & $\mathrm{I}, \mathrm{I}$ & & \\
\hline \multicolumn{6}{|l|}{ 3.2 Marketing viral } \\
\hline Recomendar la web & 16,7 & 5,6 & $\mathrm{I}, 6$ & $I-2, I-3$ & $* *$ \\
\hline Enviar postales desde la página & 5,6 & 0,0 & 0,0 & $\mathrm{I}-2, \mathrm{I}-3$ & $* * *$ \\
\hline \multicolumn{6}{|l|}{4 CREACIÓN DE CONFIANZA } \\
\hline \multicolumn{6}{|l|}{ 4.I Copyright y seguridad } \\
\hline $\begin{array}{l}\text { Política de privacidad /Derechos reservados / } \\
\text { Aviso legal }\end{array}$ & 66,7 & 59,3 & 25,7 & $1-3,2-3$ & $* * *$ \\
\hline Copyright & 33,3 & 37,0 & 18,2 & & \\
\hline \multicolumn{6}{|l|}{ 4.2 Temporalidad y marca } \\
\hline Fecha de ultima actualización de la web & 0,0 & 0,0 & 0,0 & & \\
\hline Dominio: marca.com / marca.net & 83,3 & 87,0 & 84,0 & & \\
\hline Dominio: marca.com.es / marca.es & 16,7 & 13,0 & 14,4 & & \\
\hline Otro dominio & 0,0 & 0,0 & 0,5 & & \\
\hline E-mail propio / ...@marca & 83,3 & 100,0 & 78,6 & $1-2,2-3$ & $* * *$ \\
\hline Web e-mail / ...@otro & 16,7 & 0,0 & 20,3 & $1-2,2-3$ & $* * *$ \\
\hline \multicolumn{6}{|l|}{5 DISEÑO Y USABILIDAD } \\
\hline \multicolumn{6}{|l|}{ 5.I Navegabilidad } \\
\hline \multicolumn{6}{|l|}{ Cantidad de idiomas disponibles } \\
\hline Solo español & 16,7 & $\mathrm{II}, \mathrm{I}$ & 23,5 & & \\
\hline Español e ingles & 61,1 & 59,3 & $56, I$ & & \\
\hline 3 a 5 idiomas & 22,2 & 25,9 & 19,8 & & \\
\hline
\end{tabular}




\begin{tabular}{|l|c|c|c|c|c|}
\hline 6 o mas idiomas & 0,0 & 3,7 & 0,0 & & \\
\hline Mapa del sitio & $\mathrm{II}, \mathrm{I}$ & 27,8 & 3,2 & $\mathrm{I}-2,2-3$ & $* * *$ \\
\hline Función de búsqueda & 66,7 & 9,3 & 3,2 & $\mathrm{I}-2, \mathrm{I}-3$ & $* * *$ \\
\hline Preguntas frecuentes (FAQs) & 0,0 & $\mathrm{I}, 9$ & $\mathrm{I}, \mathrm{I}$ & & \\
\hline
\end{tabular}

Diferencias significativas entre los Grupos, según ANOVA *0,10; **0,5; ***0,0I

Tabla 7. Análisis Cluster. Grupos de Webs.

\section{Conclusiones}

En una industria intensiva en información como lo es la del turismo, las páginas webs constituyen un elemento de suma importancia para las empresas del sector, ya que mejoran su competitividad, permitiendo estar presentes en los procesos de toma de decisiones de los turistas potenciales. Además, la adopción de esta herramienta de comunicación proporciona a las empresas la posibilidad de aplicar en mayor medida un marketing relacional y viral, lo cual resulta fundamental para la supervivencia de las empresas en entornos muy competitivos.

Por lo tanto, el uso de estas tecnologías por un determinado sector puede ayudar al desarrollo tanto de su negocio principal como de actividades complementarias que permitan alcanzar ventajas competitivas que aumenten su poder de mercado. El caso del turismo del vino constituye una oportunidad única para que las bodegas mejoren la competitividad de sus negocios. Recordemos que para la industria del vino, el turismo constituye una oportunidad para crear relaciones con los consumidores, tanto actuales como potenciales, y mejorar así su éxito empresarial (Díaz, 2008). Además, el turismo del vino posee el potencial para proporcionar una ventaja competitiva a las regiones productoras, ya que incrementa los flujos turísticos de esas regiones, crea una imagen de destino turístico de calidad y sirve para desarrollar las zonas productoras (Szivas, 1999). De esta forma, aunque el turismo no constituya la principal fuente de obtención de ingresos para las bodegas, puede convertirse en una importante fuente complementaria tanto para las bodegas como para las zonas en las que éstas se sitúan (Millán y Agudo, 2006).

El turista del vino tiene un alto nivel educativo, alta renta y gran interés en el vino (Levine y Pownall, 2004; Yuan et al., 2005), e Internet es de uso común en este segmento de personas. Además, en la experiencia del turismo del vino, el primer contacto que tiene el visitante $y$ las percepciones que se forma es un elemento clave, y usualmente éste se produce en la bodega (O'Neill et al., 2002; O’Neill y Palmer 2004). Por lo tanto, las páginas webs y los e-mails ofrecen nuevas puertas o medios para establecer este primer contacto (Murphy et al., 2005). Las impresiones iniciales de los consumidores formadas a través de las páginas webs de las bodegas son muy importantes en la construcción de la confianza, valor de marca, e intenciones de compra previas a la visita de la bodega. A través de sus páginas webs las bodegas pueden desarrollar su imagen, diferenciándose de la competencia, educando al consumidor y creando interés en la bodega y en el vino (Nowak y Newton, 2008). Por lo tanto, las páginas webs son muy importantes tanto para la promoción del turismo del vino como para la venta de productos, ya que pueden ser percibidas como proveedoras iniciales de información que invitan a la visita de la bodega, acción que puede culminar con la venta directa una vez allí (Sellito, 2005).

Los resultados obtenidos en este estudio ponen de manifiesto la baja tasa de adopción de herramientas web en las bodegas de las dos regiones analizadas, ya que poco más de una tercera parte del total de las mismas ha desarrollado una página web. Por lo tanto, queda aún un largo camino por recorrer para conseguir que las webs se conviertan en un importante elemento de comunicación en este sector.

Además, las bodegas analizadas están desaprovechando el potencial de las webs para llevar a cabo estrategias de marketing relacional, creando una red dinámica entre cliente y empresa en la cual existan fuertes lazos de comunicación y relación entre ambas partes, construyendo así relaciones estables exitosas. Los aspectos con mayor nivel de desarrollo en las webs analizadas se centran en proporcionar Información de Contacto, Información de Productos y Presentación de la Empresa, estando menos enfocadas hacia las dimensiones de Creación de Valor (Información de la región y Links externos) y de Construcción de Relaciones (Comunicación y Marketing viral). Concretamente, 
menos de una quinta parte del total de las webs analizadas busca un contacto personal y a largo plazo con el cliente a través de la creación de Clubs del Vino y los que lo hacen, fallan en integrar esta actividad con las tecnologías de información y comunicación para así formar una comunidad virtual. Solo una proporción minoritaria utiliza Newsletter intentando así mantener un contacto periódico con sus clientes. Por último, una porción prácticamente insignificante de las webs posee foro, blog o perfil en Facebook u otra comunidad virtual.

De esta manera, emergen tres grupos de webs en función de su orientación principal. Como era de esperar, dados los anteriores resultados, más del $70 \%$ de las páginas analizadas pertenecen al grupo que se caracteriza por ser meramente informativo. Esto es, únicamente emplean sus webs para proporcionar información básica sobre sus productos o negocios sin intentar establecer una relación con el cliente o de desarrollar negocios complementarios como sería el turismo del vino. Sin embargo, a este respecto emerge un dato alentador, ya que un $20 \%$ de las webs se encuentra orientado al turismo del vino. En esta webs se muestra al usuario una oferta turística completa, a fin de ofrecer una experiencia integral al turista. Por lo tanto, se detecta la inquietud de un grupo ya destacable de bodegas que desean potenciar esta actividad complementaria, empleando una de las principales fuentes de información externa utilizadas en la actualidad por los turistas, Internet. Finalmente, se detecta la presencia de un grupo poco numeroso de webs, menos del $10 \%$, que están claramente orientadas a la venta on-line de sus productos, sin llevar a intentos por mantener relaciones con sus clientes o por ofertarles servicios adicionales.

Las empresas del sector pueden mejorar su estrategia de marketing a través de la web poniendo a disposición de los usuarios información detallada y actualizada sobre las actividades que realizan y servicios que ofrecen, complementándolo con la oferta turística y cultural de la zona. Asimismo, pueden promover la comunicación con los clientes a través de la página, haciendo a las mismas más atrayentes, interactivas y personalizadas, por ejemplo creando Clubs del Vino y comunidades virtuales, y ofreciendo la posibilidad de realizar compras de productos o reservar las actividades de forma on-line. Deberían también invertir en elementos que aumenten la confianza en la página, lo que es importante para la repetición de visitas y las ventas on-line.
Es importante para las empresas del sector comprender que el avance de Internet introduce nuevas oportunidades de marketing y para aprovecharlas deben, en primer lugar planificar la creación e implementación del sitio web y luego considerar su mantenimiento, evaluación y gestión en el largo plazo.

La principal de las limitaciones de este trabajo se debe al carácter geográfico del ámbito de estudio. También debe considerarse que no toda la oferta enoturística existente en la región ( $y$ en Internet) está amparada bajo las Denominaciones de Origen, ya que también existen Indicaciones Geográficas Protegidas como "Vinos de la Tierra" y otras marcas privadas no acogidas a ningún tipo de certificación. Las mismas quedan fuera del presente análisis, y podrán ser incluidas en futuros estudios.

\section{Referencias}

ANTON, J. (1996). Customer Relationship Management. Prentice-Hall, New York, NY.

ANTON, J. , Hoeck, M. (2002). E-Business customer service. The Anton Press, Santa Monica, CA.

BAUER, H. H., Grether, M., Leach, M. (2000). Customer Relations through the Internet. Working paper published on the E-commerce Research Forum http://ecommerce.mit.edu/cgi-bin/viewpaper?id=38

[Accessed November 2, 2003].

BAUER, H. H., Grether, M., Leach, M. (2002). Building customer relations over the Internet. Industrial Marketing Management, 3I(2), PP. I55-I63.

BELLMAN, S., Rossitier, J. R. (2004). The Web Site Schema. Journal of Interactive Advertisig, 4(2) http://www.jiad.org/article48 [Accessed January 17, 20I0].

BHATTACHARYA, C. B., Bolton, R. N. (2000). Relationship Marketing in Mass Markets. Handbook of Relationship Marketing, Sheth J. N. y Parvatiyar A. (eds.), Sage Publications: Thousand Oaks, CA, Pp. 13-42.

BUHALIS, D., Law, R. (2008). Progress in Information Technology and Tourism Management: 20 years on and 10 years after the Internet. The state of e-Tourism research. Tourism Management. 29(4), pp. 609-623.

CONNELLY, P .J., Joguer, T. (2001). Can CRM Win and Retain Loyal Repeat Costumers?. Info World, 17 April, Pp. 58-9. 
CUSACK, M. (1998). On-line Customer Care. ASQ Quality Press, Milwaukee, WI.

DÍAZ, R. J. (2008). Potencialidad e Integración del Turismo del Vino en un Destino de Sol y Playa: El Caso de Tenerife. Revista de Turismo y Patrimonio Cultural, 6(2), pp. 199-2I2.

EGATUR (2008). Encuesta de Gasto Turístico. http://iet.tourspain.es [Accessed January 10, 2010].

FEINBERG, R., Kadam, R. (2002). E-CRM Web Service Attributes as Determinants of Customer Satisfaction with Retail Web Site. International Journal of Service Industry Management, I3(5), pp. 432-45I.

GETZ, D. (2000). Explore Wine Tourism: Management, Development and Destinations. Cognizant Communication Corporation, New York.

GETZ, D., Carlsen, J., Brown, G., Havitz, M. (2008). Wine Tourism and Consumers. In A.G. Woodside, \& D. Martin (Eds.), Tourism management: Analysis, behaviour and strategy. Cambridge, MA: CABI., pp. 245-268.

GILBERT, D. C., Powell-Perry, J., Widijoso, S. (1999). Approaches By Hotels To The Use Of The Internet As A Relationship Marketing Tool. Journal of Marketing Practice. Applied Marketing Science, 5(I), Pp. 2I-38.

HAIR, J., Anderson, R., Tatham, R., Black, W. (2000). Análisis Multivariante. Edit. Prentice Hall.

HALL, C. M., Johonson, G., Cambourne, B., Macionis, N., Mitchel, R., Sharples, L. (2000). Wine Tourism: An Introduction. C. M., Hall, L. Sharples, B. Cambourne, N. Macionis. Wine Tourism Around the World. Oxford: Butterworth Heinemann.

HAN, J. H., Mills, J. E. (2006). Zero Acquaintance Benchmarking at Travel Destination Websites: What is the First Impression that National Tourism Organizations Try to Make?. International Journal of Tourism Research, 8(6), 405-430.

HANSON, W. (2000). Principles of Internet Marketing. Southwest College Publishing, Cincinnati Ohio.

HASHIM, N. H., Murphy, J., Law, R. (2007). A Review of Hospitality Website Design Frameworks. In P. O'Connor, W. Hopken, U. Gretzel (Eds.), Information and communication technologies in tourism New York: SpringerWien. pp. 219-229.

HU, C., Han, Y. T., Jang, S. S., Bai, B. (2005). E-Relational
Characteristics on Hospitality and Tourism Program Web Sites. Journal of Hospitality \& Tourism Research, 29(4), Pp. 508- 522.

IKERFEL (2005). Mercado Actual y Potencial en el Turismo Enológico en La Rioja. Actas del I Salón Internacional de Turismo del Vino, Logroño, 2I-24 abril de 2005.

JEONG, M., Oh, H., Gregoire, M. (2003). Conceptualizing Web Site Quality and its Consequences in the Lodging Industry. International Journal of Hospitality Management, 22(2), pp. $161-175$.

KIM, D .J., Kim, W. G., Han, J. S. (2007). A Perceptual Mapping of Online Travel Agencies and Preferente Attributes. Tourism Management, 28(2), pp. 59I-603.

KIRBY, J., Marsden, P. (2005). Connected Marketing: The Viral, Buzz and Word Of Mouth Revolution, ed ButterworthHeineman. Reino Unido.

KITTLE, B., Ciba, D. (1999). Relationship Marketing in Higher Education via the World Wide Web: A Study of Home Pages Examining Student Retention Strategies. Proceedings of the 1998 Symposium for the Marketing of Higher Education, American Marketing Association, Chicago, pp. 165-175.

KLASSEN, M. L. (2002). Relationship Marketing on the Internet: The case of top- and lower-ranked US Universities and Colleges. Journal of Retailing and Consumer Services, 9(2), pp. 8I-85.

LEVINE, M., Pownall, S. (2004).Wine Industry Outlook: Consumption Demographics, Market Segmentation, Trends and Opportunities. Wine Industry Outlook Conference. Darling Harbour, Sydney Australia. November 24.

MARTíN, D. (1999). Las Tecnologías de la Información y el Turismo. Estudios Turísticos, 142, pp. 3-24.

MILLÁN, G., Agudo, E. (2006). El turismo rural en la provincia de Córdoba: dos metodologías para conseguir la multifuncionlidad del territorio rural. $4 I^{a}$ Asamblea Anual América Latina \& Unión Europea. Oportunidades y Desafios.

MURPHY J., Tan I. (2003). Journey to Nowhere? Electronic Customer Service by Travel Agents in Singapore. Tourism Management, 24(5), pp. 543-550.

MURPHY, J., Ho, P., Chan, C. (2005). Competitive Analyses for Marketing Electronic Wine Tourism. International Journal of Wine Marketing, 17(3), pp. 39-54. 
MURPHY, J., Raffa, L., Mizerski, R. (2003). The Use of Domain Names by E-branding by the World's Top Brands. Electronic Markets, I3(3), pp. 30-40.

NIELSEN, J. (2000). Designing Web Usability. New Riders Publishing. Indianapolis. Indiana.

NOWAK, L. I., Newton, S. (2008). Using winery web sites to launch relationships with Millennials. International Journal of Wine Business Research, 20(I), Pp. 53-67.

NYSVEEN, H., Methlie, L. B., Perdersen, P. F. (2002). Tourism Web Sites and Value-added Services: the Gap between Customer Preferences and Web Sites Offerings. Information Technology and Tourism, 5(3), Pp. 165-174.

O'CONNOR, P. (2003). On-line Pricing: An Analysis of Hotel-company Practices. Cornell Hotel and Restaurant Administration Quarterly, 43(3), 33-45.

O'NEILL, M., Palmer, A. (2004). Wine Production and Tourism: Adding Service to a Perfect Patership. Cornell Hotel and Restaurant Administration Quarterly, 45(3), pp. 269284.

O'NEILL, M., Palmer, A., Charters S. (2002). Wine Production as a Service Experience - The Effect of Service Quality on Wine Sale. Journal of Services Marketing, 16(4), Pp. 342-362.

OLSEN, M. D., Connolly, D. J. (2000). Experienced-based Travel. Cornell Hotel and Restaurant Administration Quarterly, 4 I (I), Pp. 30-40.

PALMER, J. W. (2002). Web Site Usability, Design and Performance Metries. Informatios System Research, 13(2), Pp. 155-167.

PEPPERS And Rogers Group, Phocuswright INC. (200I). One to One in Travel. The PhocusWright Report Series, 3(I).

REICHHELD, F. F. (1996). The Loyalty Effect. Cambridge, Harvard Business School Press.

REINDERS, J., Baker, M. (1998). The Future for Direct Retailing of Travel and Tourism Products: The Influence of Information Technologies. Progress in Tourism \& Hospitality Research, 4(I), Pp. I-I5.

RICHARDSON, O. (2002). Utilisation Of The World Wide Web By Wine Producers. International Journal of Wine Marketing, I4(3), pp. 65-79.

SCHARL, A., Wöber, K. W., Bauer, C. (2004). An Integrated Approach to Measure Web Site Effectiveness in the European Hotel Industry. Information Technology \& Tourism, 6(4), pp. 257-27I.

SCHEGG, R., Steiner, T., Frey, S., Murphy, J. (2002). Benchmarks of Web Site Design And Marketing by Swiss Hotels. Information Technology \& Tourism, 5(2), pp. 73-89.

SELLITTO, C. (2005). A Study of Emerging Tourism Features Associated with Australian Winery Websites. Information Technology \& Tourism, 7(3-4), PP. 157-170.

SELLITTO, C., Wenn, A., Burgess, S. (2003). A Review of the Web Sites of Small Australian Wineries: Motivations, Goals and Success. Information Technology and Management, 4(2-3), 2I5-232.

SWIFT R, S. (200I). Accelerating Customer Relationship Using CRM and Relationship Technologies. Prentice Hall, PTR, Englewood Cliffs, NJ.

SZIVAS, E. (1999).The Development of Wine Tourism in Hungary. International Journal of Wine Marketing II(2), PP. 7-17.

TSCHOHL, J. (200I). E-services. Best Sellers Publishing, Minneapolis, MN.

VEEN, J. (2000). The Art and Science of Web Design. New Riders Publishing. Indianapolis. Indiana.

WANG, F., Head, M., Archer, N. (2000). A Relationship Building Model for the Web Retail Marketplace. Internet Research. Electronic Networking Applications and Policy, 10(5), Pp. 374-384.

YUAN, J., Cai, L. A., Morrinson, A. M., Linton, S. (2005). An Análisis of Wine Festival Atened Motivations: A Synergy of Wine, Travel and Special Events?. Journal of Vacation Marketing, I I (I I), pp. 4I-58. 